\title{
Do conteúdo à recepção: o guia do livro didático de história (2005/2008)
}

\author{
Jútia Helena Simões MOREIRA ${ }^{1}$ \\ Jínia Sales PEREIRA ${ }^{2}$
}

\section{RESUMO}

O presente artigo trata das mudanças pelas quais passou o Guia do Livro Didático de História de 2005 e de 2008, sejam elas relacionadas a aspectos estruturais ou específicos do conhecimento histórico e pedagógico. Trata também da recepção desse guia por professores da Educação Básica, com abordagem de usos que os docentes fazem deste impresso, assim como quais são os fatores que influenciam e/ou interferem no processo de escolha do livro didático de História.

Palavias-chave: PNLD - Guia do Livro Didático de história 2005/2008 - usos do Guia - processo de escolha do livro.

\section{O Programa Nacional do Livro Didático}

Políticas públicas para a distribuição e confecção do livro didático não são, de fato, recentes. As mais antigas remontam ao Estado Novo, quando o livro didático era visto como auxiliar na formação da nacionalidade e na modelagem de condutas. Da mesma forma, no período ditatorial destacava-se por seu caráter extremamente político-ideológico. As políiticas passaram por sucessivos processos de desenvolvimento, até que chegaram à distribuição gratuita de livros para as escolas públicas das redes federal, estadual e municipal, dessa vez com especial atenção para com os erros conceituais, preconceitos e desatualizações (MIRANDA, DE LUCA, 2004).

Tal como hoje o compreendemos, em linhas gerais, o Programa Nacional do Livro Didático data de 1985, quando deixa de ser o Plidef (Programa do Livro

\footnotetext{
' Graduada em História pela Universidade Federal de Minas Gerais e pesquisadora vinculada ao Labepeh (Lahoratório de Listudos e Pesquisas em Ensino de História), Faculdade de Educação/UFMG. juliafafich@ yahoo.com.br

2 I outor: em História, professora da Faculdade de Educação da UFMG. É uma das coordenadoras do Labepeh, Laboratório de Estudos e Pesquisas em Ensino de História, Fae UFMG. juniasales@fae.ufmg.br
} 
Didático para o Ensino Fundamental) e passa a indicar livros, a reutilizá-los, a aperfeiçoar as técnicas para a produção e a estender a oferta para os alunos de $1^{\mathrm{a}} \mathrm{e} 2^{\mathrm{a}}$ séries. 0 processo decisório passa para o controle da FAE (Fundação de Assistência do Estudante, que hoje é o Fundo Nacional de Desenvolvimento da Educação), garantindo o critério de escolha dos livros pelos professores (embora a avaliação pedagógica das coleções tenha começado a ser feita em 1996). 0 programa é gerido nacionalmente por duas instâncias, atualmente: o MEC (Ministério da Educação) responsável por coordenar, instituir os critérios e elaborar o edital (também informado e orientado por Universidades), ou seja, planejar e normatizar; e o FNDE (Fundo Nacional de Desenvolvimento da Educação), responsável pela captação de recursos e execução das ações que envolvem o processo de escollha, a compra e a distribuição das obras.

0 programa se realiza em várias etapas antes da chegada dos livros às escolas. Começa com a inscrição das editoras ao Edital, passa pela triagem, pela avaliação pedagógica gestada pelas Universidades conveniadas ao Mec, pela confecção do Guia, pela escolha dos professores, pelo pedido ao Mec, pela aquisição e pela produção, distribuição e uso nas escolas. A responsável por escolher os especialistas que farão a análise dos livros é a SEB (Secretaria de Educação Básica) em parceria com as universidades públicas; nesse ponto, as obras com erros graves (equívocos conceituais, reprodução de preconceitos, desatualizações, etc) são excluídas. É fato que há muita desinformação sobre o processo de seleção, e, segundo afirma o próprio Ministro da Educação, é importante ressaltar que nenhum servidor do Ministério da Educação participa da seleção dos livros por ser funcionalmente impedido sob pena de direcionamento da escolha do professor (HADDAD, 2007). No processo de avaliação sob edital, cada obra é enviada sem capa à coordenadoria de área do PNLD que estabelece a dinâmica de avaliação geralmente executada pela apreciação da obra por pelo menos dois pareceristas selecionados pela Universidade; nesta fase cada obra não pode receber pareceres contrários, embora possa receber ressalvas.

No Guia do Livro Didático constam, portanto, as obras consideradas adequadas pelos pareceristas do PNLD, em conformidade com o edital e com os parâmetros mínimos exigidos para promoção do ensino-aprendizagem em cada área do conhecimento.

O processo de escolha dos livros didáticos a serem utilizados em cada escola 
no âmbito do PNLD afirma o princípio de protagonismo dos professores. A recomendação é que os professores façam uma escolha compartilhada nas escolas, embora saibamos que as mais diferentes injunções compareçam a esse processo de escolha do livro. Verificamos desde a indicação simples por um professor (por exemplo, de obra já convencionalmente utilizada por ele naquela ou em outra escola) até a realização de fórum de escolha de livros didáticos de uma rede municipals.

Após a escolha feita pelos professores, os livros são enviados às escolas ${ }^{4}$. Para as edições analisadas (2005/2008), espera-se que cada aluno tenha recebido um exemplar das seguintes disciplinas: Português, Matemática, Ciências, História e Geografia. Inevitavelmente, tanto pelo fato de ser o PNLD relativamente recente quanto pelos usuais problemas burocráticos, o processo de entrega apresenta situações inesperadas:

\begin{abstract}
"Pesquisas realizadas em território nacional e patrocinadas pelo próprio MEC indicaram, em momentos distintos, que há problemas incontestáveis envolvendo atrasos sistemáticos na edição e distribuição do guia para as escolas ${ }^{5}$, incongruências de toda ordem no tocante à escolha feita pelo professor e envio das obras pelo FNDE, atrasos na recepção dos livros, por parte das escolas, bem como fragilidades envolvendo o processo de utilização das obras enviadas que chegam até mesmo a ser desprezadias e desconsideradas pelos professores." (MIRANDA, LUCA, 2004, p. 24)
\end{abstract}

\footnotetext{
o fórum foi organizado em 2006 na cidade de Pedro Leopoldo após abordagem da secretaria municipal de liducação do município pela equipe de pesquisadores do Labepeh. Nesse caso, verificou-se que a própria ação de pesquisa gerou naquela realidade a instauração de una dinâmica diferenciada de promoção de debates a respeito da escollha do livro didático com favorecimento das opções dos professores.

Neste caso, geralmente há duas opções de escolhas. Para receber o livro indicado em primeira escolha ou mesmo em segunda opçĩo, os professores contarão durante o processo com a existência de interesse e disponíbilidade da editora detentora dos direitos daquele livro em distribuir a obra na região em que a escola está. Não sendo possível esse atendimento, a escola recebe geralmente a obra didática daquela área do conhecimento mais alotada na região em que a escola está. Esse processo nem sempre agrada aos professores, sendo possível que recelam exatamente obras contrárias ao projeto pedagógico ou propostas educativas em curso na escola.

Algumas pesquisas apontann também para a inexpressiva utilização do Guia do Livro Didático como informante central do processo de escolla do livro didático de história e de língua portuguesa. (BATISTA, 2004; PEREIRA, SIMAN, 2007).
} 
No Guia, apresentam-se os critérios, as resenhas das coleções aprovadas e a ficha de avaliação. 0 Guia é um impresso, portanto, que tem como público leitor os professores em atuação nas escolas públicas do país; é publicado de três em três anos e seu pressuposto, assim como do PNLD como um todo é, além de fornecer o material para as escolas em momento de seleção de materiais didáticos para o ano seguinte, convidar o professor para a realização da escolha do material didático realizando uma análise que confronta o que ele encontra nos livros didáticos enviados pelas editoras à escola em momento pré-escolha e o que ele poderá ler e refletir a partir do que está contido no Guia do PNLD. Espera-se também que a leitura do Guia possa subsidiar a escolha dos docentes, favorecendo a dinâmica de escolha coletiva, uma vez que a escola elege uma mesma coleção didática por área para adoção por todos os professores/turmas. Sua pretensão é de ser operacional, mas não pode expressar nenhum tipo de preferência por uma ou outra coleção, embora, contraditoriamente em algumas edições do PNLD ocorra uma certa hierarquização das coleções, com atribuição de valores (como ótimo, bom, muito bom, etc) ou mesmo a atribuição de estrelas (como ocorreu em edições anteriores). No entanto, o Guia é fruto de um processo de apreciação, seleção e recomendação, feito para subsidiar o(s) professor(es) no momento da escolha, embora em algumas localidades do país este importante recurso chegue após o prazo regular de escolha ou, o que é motivo de reflexão, é muitas vezes pouco utilizado pelos professores.

\section{De 2005 a 2008: mudanças}

O PNLD é, como já vimos, um programa relativamente recente, sendo que a própria avaliação pedagógica de livros didáticos somente passou a ser feita a partir de 1996. Ao analisar as modificações entre o Guia do Livro Didático de 2005 e o Guia do Livro Didático de 2008, para 5ª a 8. ${ }^{a}$ séries, deve-se ter em mente que os Guias são produções vinculadas à consolidação de uma política pública, fazem parte de um processo mais amplo de análise e distribuição de materiais pelo Ministério da Educação, que, como já é sabido, está em contínuo aprimoramento. Tendo isso claro, estudaremos neste artigo as mudanças dos guias do Livro Didático de História de 2005 e de 2008, de $5^{\text {a a }} 8^{\text {a }}$ série, com especial atenção para os critérios de avaliação explicitados nos dois Guias para a área de história 
e buscando compreender as relações que comumente estabelecem os professores com este impresso.

Antes de falarmos especificamente das mudanças, é importante lembrar do contexto de produção dos dois guias. Ambos foram elaborados sob a presidência de Luiz Inácio Lula da Silva, ainda que durante dois mandatos distintos (os guias são datados de 2004 e 2007, respectivamente). 0 Ministro da Educação passou a ser Fernando Haddad, antes Secretário Executivo, e houve mudanças na equipe técnica de produção do guia. Mais relevante, porém, éa transformação da equipe de pareceristas: ainda que sob a responsabilidade da mesma universidade (Universidade Federal do Rio Grande do Norte), apenas 1 dos 17 pareceristas de 2005 permaneceu na equipe do guia de 2008, que, por sua vez, conta com 29 pareceristas.

Outro ponto relevante éa Lei $10.639 / 03^{6}$, que, apesar de ter sido sancionada em 2003, passa a vigorar de fato entre um programa e outro e influencia mais especificamente o último guia - já que as Diretrizes Curriculares correlatas à lei foram publicadas em outubro de 2004.

As transformações são claras quando comparamos os dois guias. Estão presentes na organização, em relação às coleções aprovadas, aos critérios avaliativos e aos métodos de análise e apresentação das coleções. Das 22 coleções aprovadas em 2005, 11 foram aprovadas em 2008 - sendo que 1 foi reformulada. Já o guia de 2008 aprovou 19 coleções, redução de 3 em relação a 2005. A permanência de apenas 11 coleções de um guia para o outro, assim como a aprovaçã̃o de 8 novas coleções, aparece como indício de mudanças mais profundas que podem estar vinculadas ao aperfeiçoamento dos critérios de avaliação (de qualquer outra forma seria difícil de explicar a não-aprovação de 11 coleções, já que algumas raramente são reestruturadas em função da aprovação).

Iniciaremos a análise pela organização dos guias. 0 Guia de 2005 compõese das seguintes sessões: Carta ao professor; Resenhas das obras aprovadas; Critérios de Avaliação; Ficha de Avaliação; e Referências Bibliográficas. Já o Guia de 2008 apresenta-se da seguinte forma: Apresentação; Critérios e Metodologia de Avaliação; Análise das Coleções (geral, a partir dos critérios); Resenhas das Coleções (individualmente e subdivididas em grupos de acordo com a organização do conteúdo); Ficha de Avaliação; e Referências Bibliográficas.

\footnotetext{
A lei institui o ensino obrigatório da História e Cultura Afro-brasileira nas escolas, em especial na área de História, Educação Artística e Literatura.
} 
A "Carta ao professor" do guia de 2005 explicita que as resenhas contêm informações sobre as características gerais das coleções, os aspectos metodológicos e sobre os elementos positivos e negativos de cada obra. Aos pareceristas, dentre outras coisas, ficou o encargo de observar se alguma obra possuía problemas que pudessem comprometer gravemente a utilização dos livros em sala de aula. Houve a preocupação, nesse guia especificamente, com hierarquizações e comparações entre as coleções - as estrelas e menções distintivas, utilizadas em edição anterior do PNLD, foram excluídas e as coleções foram analisadas individualmente (sendo este um pressuposto da avaliação da equipe de pareceristas daquela edição). Parece-nos que a pretensão era de que o guia funcionasse mais como um catálogo no qual as obras estariam organizadas em ordem alfabética e com análises peculiares às características de cada obra, e não como parte de um procedimento classificatório e distintivo, como foram os guias que o antecederam (MIRANDA, LUCA, 2004, p. 127). De fato, a pretensão é cumprida, já que as coleções não foram hierarquizadas ou comparadas. Tais preocupações, porém, não se repetem. no Guia de 2008.

O guia de 2008 traz, na sua própria organização, indícios daquilo que se procurou evitar em 2005. É justificado na apresentação que a obra se organizará com um formato diferente das anteriores para ajudar na escolha do professor, de maneira que ele opte por uma coleção que se adapte melhor à realidade escolar na qual está inserido. Porém, o que se verifica é algo similar ao movimento avaliativo classificatório.

Com relação à organização, o Guia apresenta as coleções aprovadas subdivididas em grupos de acordo com a organização do conteúdo: História Temática (em que as propostas são organizadas por temas); História Integrada (em que as propostas tratam da História Geral, da América e do Brasil concomitantemente e não necessariamente em ordem cronológica); História Intercalada (História do Brasil e da América junto com a História Geral em ordem cronológica crescente, mas sem relacionamento entre os conteúdos); e por fim História Convencional (em que os conteúdos das coleções são definidos de acordo com a série). Essa escolha foi feita com a justificativa de ser o conhecimento histórico amplo, e não determinar conteúdos e estruturas a serem abordados nos programas escolares.

Outra questão importante é a opção por fazer uma análise geral das coleções. Nesse ponto, apresenta-se um texto inicial com a análise das coleções na qual estão em destaque os seguintes elementos: a diversidade na organiza- 
ção dos conteúdos, as propostas para o livro e para a formação da cidadania, a editoração e os manuais do professor. Esse texto trata de eixos de destaque entre as coleções, especialmente em relação aos princípios históricos, objetivos e propostas, ao aspecto e às estratégias pedagógicas, às narrativas históricas e à diversidade de atividades didáticas. Posteriormente, o guia é dividido em sessões que correspondem a cada grupo pré-definido e, antes das resenhas individuais, apresenta-se uma avaliação geral das obras correspondentes a partir dos critérios comuns de avaliação. Nesse sentido, as coleções acabam por ser comparadas já que são previamente agrupadas por similaridade de organização do conteúdo e analisadas como um grupo coeso, no qual algumas cumprem, de dada forma ou não, os critérios determinados. 0 professor tem acesso a um texto inicial no qual as coleções são sistematicamente agrupadas e comparadas, fato que difere do objetivo já explicitado em momentos de amadurecimento e discussões do Programa de Avaliação do Livro Didático de evitar recomendações prescritivas ou mesmo de induzir à escolha pelo ranqueamento.

Outro ponto que também leva à reflexão é a opção por apresentar no início do guia un cuadro síntese das coleções com os resultados alcançados a partir dos critérios - em cada um deles as coleções foram consideradas "Ótima" (azul) ou "Boa" (Verde), ou "Suficiente" (laranja" ou "Não" (vermelho), conforme se verifica a seguir.

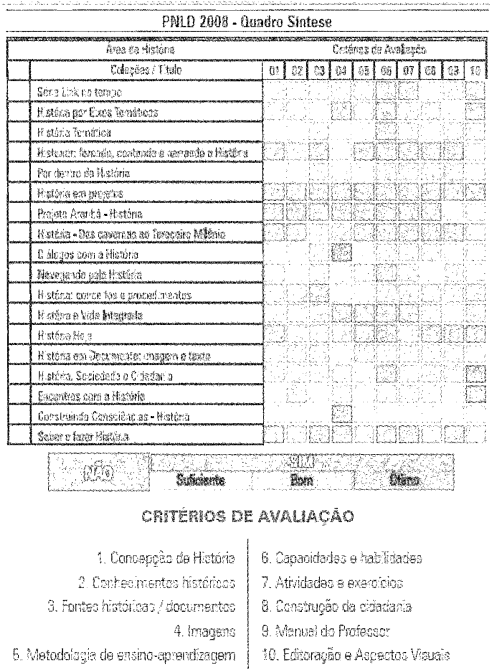

Guia do livro didático de História 2008, p.17 
Esse quadro, apesar de ter sido uma tentativa de sistematização das apreciações do guia, ao chegar às mãos do professor pode favorecer uma análise meramente instrumental - como, por exemplo, gerar a contagem de quantos azuis uma coleção recebeu, ou, após a escolha, gerar a conferência por parte do professor se a opção foi bem avaliada de acordo com o quadro?.

Os critérios de avaliação de 2008, por sua vez, appresentam alterações e, sob nossa perspectiva, amadurecimento em relação a 2005.

Em 2005 os critérios ainda tinham sua base de sustentação quase que exclusivamente na "existência de erros de informação, conceituais ou de desatualizações graves; veiculação de preconceitos de gênero, condição social ou etnia, bem como de quaisquer formas de proselitismo e, por último, verificação de incoerências metodológicas graves entre a proposta explicitada e aquilo que foi efetivamente realizado ao longo da obra." (MIRANDA, LUCA, 2004, p. 128)

Os aspectos intrínsecos ao conhecimento histórico estavam ligados mais ao cuidado com os conceitos, ao trabalho com as fontes, ao desenvolvimento de noções de tempo e espaço, à reflexão sobre a ética e a cidadania e a coerência das propostas metodológicas e a variedade de tendências historiográficas. No Guia 2008 os critérios estão mais focados nas especificidades da História como disciplina escolar e como conhecimento. Neste caso, os critérios foram divididos em 10 pontos: concepção de História, conhecimentos históricos, fontes históricas, imagens, metodologia de ensino-aprendizagem, capacidades e habilidades, atividades exercícios, construção da cidadania, manual do professor e editoração e aspectos visuais.

Além do que é ressaltado nos critérios de 2005, ou seja, da percepção e compreensão de conceitos, dá-se atenção aos processos, sujeitos, tempos, espaços e problemas. 0 trabalho com as fontes é visto como necessário para a construção do conhecimento e deve demonstrar a diversidade da sociedade brasileira. As atividades são avaliadas para além da sua correta formulação, mas pela responsabilidade por abordar a diversidade das experiências humanas, a temática das relações étnico-sociais e de gênero, estimular o respeito, a tolerância, a liberdade e discutir a historicidade das experiências sociais.

1)ados da pesquisa coletados por Lana Mara Castro Siman, Marco Antônio Silvá eJúnia Sales Pereira sinalizam para essa forma de apropriação do guia (2007). 
Após essa breve exposição é possivel concluir que houve transformações e modificações nos critérios de avaliação e também na própria organização do guia de 2008. No que diz respeito aos critérios, foram definidos e delineados por elementos específicos, não só do conhecimento histórico, mas também do ofício do historiador (a História como disciplina e como produção de conhecimento). Na elaboração do guia é observada a sua funcionalidade e operacionalidade para o professor. Trataremos agora, portanto, do universo dos usos que os professores fazem do guia do Iivro Didático, ressaltando que não temos por objeto de análise a realidade escolar e seus complicadores, como citado acima.

\section{Os professores, leituras e usos do Guia}

É raro encontrar pesquisas que tratem do processo de escolha do livro didático a partir da perspectiva do docente, mesmo tendo claro que é ele o destinatário do guia. 0 próprio programa convida o professor à escollha e fornece o Guia, elaborado por especialistas e professores universitários, para facilitar a decisão. Cabe, contudo, compreender quais são os usos (ou não-usos) que os docentes fazem desse material.

o processo de escollha é extremamente complexo e influenciado por uma série de fatores, sejam eles o cotidiano do trabalho docente, as condiçoes escolares ou fatores propriamente sócic-culturais. Os professores fazem uso de critérios muitas vezes diferenciados daqueles que o Programa Nacional de Livros Didáticos prioriza. Uim dos motivos dessa divergência talvez seja a falta de conhecimento do programa pelos professores, sobretudo de como se dá o processo de confecção do próprio Guia. Aliam-se a isso os problemas de distribuição, já que muitas vezes o guia chega às escolas após a escolha. Mas há também o fato de que os professores estão inseridos em dinâmicas escolares diversas, com demandas e perspectivas de atuaç̧ão profissional que configuram a eleição de critérios de escolha do livro didático vinculados à docência, não exatamente afinizados ou idênticos àqueles utilizados no processo de aprovação dos livros sob Edital. É claro, não se trata neste caso de dizer que os critérios dos professores são menos válidos que aqueles

\footnotetext{
* Pescuisá realizalda por Pereira. Silva S Siman, 2007 revela, a título de exemplo, que em regiões de acirramento da violência urbana alguns professores tendem a escolher livros didáticos adequados a uma realidade social em cue não há possibilidade de recomendação de realização de trabalhos extra-turno, significando que a atividade de pesquisa se realiza estritamente no horário da aula.
} 
utilizados pelos pareceristas. Trata-se de entender que há lógicas diferentes informando a elaboraçã̃o dos critérios nos dois casos ${ }^{8}$.

Um importante estudo sobre o tema foi feito por Antônio Augusto Gomes Batista em "Livros de alfabetização e de Português: Os professores e suas escolhas" (2004). Apesar de tratar do processo de escolha dos livros de português e de matemática durante o PNLD 2000/2001, alguns dados podem ser considerados similares àqueles verificados na análise da escolha de livros de outras disciplinas. Nesse estudo ressalta-se a perspectiva do processo pelo professor e os seus princípios de apreciação e avaliação dos manuais recebidos nas escolas. Com o resultado de sua pesquisa prevalece a indicação de que os docentes têm total, ou parcial, desconhecimento do processo de avaliação do livro didático - esse dado aparece como consequiência de dois importantes fatores: o Guia não chega, ou não chega a tempo, nas escolas; os professores preferem fazer uma análise direta dos livros enviados pelas editoras.

0 autor aponta cinco motivos para a não-utilização do guia pelos professores: primeiro, a questão da hierarquia nas escolas - os superiores não teriam difundido o guia entre os professores; segundo, a preferência pela consulta direta das obras distribuídas pelas editoras; terceiro, a falta de tempo - prazo curto entre a chegada do guia na escola e o envio da escolha ao FNDE; quarto, o desconhecimento do processo de escolha e a ausência de informaçoes sobre 0 instrumento realizado para esse processo; e quinto, a instabilidade no cotidiano - as constantes mudanças de funções dentro do ambiente escolar. Além disso, apareceu uma única resposta que pode reforçar todas as afirmações anteriores: de que não vale à pena consultar o guia, por ele ser uma espécie de peça publicitária das editoras.

Ainda segundo Batista, os professores não vêem o guia como importante ou indispensável para a realização da escolha. Recorrentemente encontrou o apelo para livros que tenham vínculos com a realidade do aluno, com o contexto escolar e com o centro de interesse do professor. Somam-se a isso inúmeras críticas, na época, ao sistema de classificação do programa, em que as obras eram indicadas como "Recomendadas com distinção", "Recomendadas" e "Recomendadas com ressalvas", além de serem acompanhadas por estrelas. Há resistência dos docentes em relação às ações do MEC para orientação da escolha (o que pode ser explicado

"BATTSTA, Antônio Augusto Gomes; WL, Maria da Graça Costa. Livros de alfabetização de Portugutês: os professores e suas escollaas. p. 48 Belo Horizonte: Ceale/Autêntica, 2004. 
por um distanciamento entre a lógica acadêmica e a lógica escolar ${ }^{9}$ ), por priorizarem o contato direto com o livro, prezando, dessa forma, pela autonomia e independência no processo de escolha. Fatores que ameaçam a autonomia são sistematicamente rejeitados: por exemplo, a ação das secretarias de educação e órgãos do sistema de ensino e as ações das editoras (reunião com autores e eventos para orientação pedagógica).

Em suma, em relação ao processo de escolha do PNLD 2000/2001, o autor conclui: os professores dão pouca, ou nenhuma, importância às categorias de classificação do guia; as resenhas dos livros podem ser muito importantes (por não interferir impositivamente entre o professor, o livro e o processo); e o guia não parece ter constituído um dos elementos que basearam a tomada de decisão dos professores, tanto pela ausência de informações sobre a avaliação ministerial, quanto por não levar em conta as particularidades da cultura escolar.

Há estudos mais recentes, porém, que podem trazer mais respostas para como se dá o uso do guia pelos professores. É o caso da pesquisa de Lana Mara de Castro Siman, Júnia Sales Pereira e Marco Antônio Silva sobre "Livros didáticos de História e processos de escolha: atores, cenários e tramas" (2007), da Faculdade de Educação da UFMG. Discutem os dados sobre a escolha do livro didático por professores do Ensino Fundamental da região metropolitana de Belo Horizonte, Minas Gerais, compreendendo-a como um processo que sofre influências, interferências e incentivos os mais variados. Os autores ressaltam que para pesquisar a escolha dos docentes é necessário levar em consideração que eles usam critérios muitas vezes diferenciados daqueles definidos pelo programa e que suas apreciações estão vinculadas às práticas de uso do livro em sala de aula, às condições de trabalho, às diferentes realidades escolares e às representações que fazem do livro didático.

Os resultados iniciais da pesquisa apontaram para o fato de nem todos os professores lerem o guia, ou apoiarem nele como elemento válido para a análise do livro. Porém, os autores concluem que, apesar do guia não configurar como elemento principal na escolha, os docentes criam novas práticas e maneiras de apreciação do livro didático. Ainda segundo eles,

"A compreensão inicial é de que os usos do livro didático podem referendar, informar, consolidar as ações de indicação de uma nova coleção didática pelos 
professores ou ainda de manutenção de uma mesma coleção para os anos seguintes. Os professores elencam, também a partir de dados advindos do exercício de sua prática profissional, características que consideram mais adequadas em livros didáticos e que vão sendo consideradas primordiais para que uma coleção didática seja satisfatória para (re) adoção (e pensam também num público leitor específico)" (SIMAN, Pereria e Silva).

Em uma das escolas, por exemplo, foi elaborada uma ficha pela equipe pedagógica da escola para auxiliar os professores na análise dos livros, com critérios completamente diversos daqueles utilizados no guia, como por exemplo: a criatividade, motivação, atratividade, etc. Há também fatores alheios ao livro ou a critérios de uso do livro que comparecem ao processo de escolha. Em uma das escolas pesquisadas por Siman, Pereira e Santos, os professores de história seguiram a recomendação do professor com maior tempo de casa; em outro caso, os professores das séries iniciais do ensino fundamental seguiram a recomendação dada pelo professor de história da mesma escola que atua com séries de Ensino Médio (considerando-o, portanto, um profissional impactado pelo trabalho das séries iniciais).

Im problema que os autores trazem à tona é o desconhecimento do próprio processo de elaboração do guia, já que muitos professores acreditam que se trata de um material das editoras ou que éfeito diretamente pelo MEC, e que, portanto, transmite concepções do governo vigente. Ao lado disso está o complicador de que o guia e programa sofrem constantes transformações e reformulações - dado que, apesar de positivo, pode interferir ou criar obstáculos na recepção e apropriação do impresso pelos docentes. Há professores bastante preocupados com a extensão dos Guias (alguns com mais de 300 páginas para uma única área), sobretudo diante do pouco tempo que têm para lê-los todos, apreciar os livros didáticos (quando os recebem na escola a tempo) e processar nas negociações com os pares na escola para que esta escolha se efetive.

São inúmeros os fatores que interferem no processo de escolha dos professores, sejam eles elementos advindos do cotidiano escolar (sucessivas mudanças de funções, a violência, a estrutura da escola, etc.), ou questões plenamente culturais (desconfiança, crença de que o Guia é uma tentativa de ingerência governamental, que se impõe perante a autonomia e independência do professor), o fato é 
que o guia não atinge plenamente a sua pretendida funcionalidade. Pode-se suspeitar que esse fator pode se ocorrer não apenas por razões logísticas (o guia não chega ao professor de fato a tempo de processar a escolha... ou o professor não tem tempo de ler o guia integralmente e discuti-lo com os pares...) ou por razões ideológicas (o professor não crê no guia como fonte de pesquisa, consulta e orientação). Há, a nosso ver, razões que têm relação também com a forma como o guia se estrutura (o ranqueamento pode ser um dos fatores dificultadores...), mas há que se considerar em especial o fato de que o Guia do PNLD não apresenta ao professor informações efetivas a respeito dos perfis dos livros didáticos (formas de organização dos conteúdos, maneiras de abordagem, escolhas metodológicas envolvidas nos processos de confecção dos livros didáticos, diálogo entre texto e atividade na composição do caderno dos alunos, etc).

As falas de professores atentam para o dado de que muitas vezes não têm acesso ao guia, ou não o utilizam como instrumento de análise - acabam por fazer um uso sistematizado, quando a escolha já foi confirmada (é o caso da consulta do quadro síntese):

"olhamos os livros 'nas janelas', escolhemos comparando...; outros levaram para casa; o Guia só chegou junto com a última remessa de livros. Recebemos dois exemplares do Guia por escola. Escolhemos o livro e depois vimos o Guia e nos perguntamos..." (Professora S., Escola Municipal José Elias, Pedro Leopoldo, MG, 06/07/2007) (SIMAN, PEREIRA e SILVA, p. 12)

Por fim, os autores lembram que apesar de todos os problemas que afetam a realidade escolar, os professores conferem uma especial atenção para o processo de escolha do livro, seja através do guia ou com ancoragem em outros recursos ou estratégias de apreciação. Consideramos que algumas reações dos docentes frente ao guia devem-se também ao fato de que a escolha do livro didático é um raro momento de exercício da sua autonomia em que seu papel como educador independente é reforçado, no diálogo ou até mesmo em confronto com os pares, uma vez que é responsável pela escolha de um dos principais elementos do trabalho escolar.

Contudo, consideramos também contraditório o fato de que, apesar de afirmar a autonomia e protagonismo docente no processo de escolha do livro 
didático, não necessariamente temos guias do livro didático orientados para este profissional-leitor, com vistas à promoção do diálogo efetivo entre esse impresso e as demandas da prática realidade escolar, sobretudo em diálogo com as expectativas desse leitor que pensa em sua sala de aula real quando escolhe o livro didático.

\section{Considerações finais}

Configurando-se como mais um dos elementos da busca pela democratização do ensino, o PNLD é um programa relativamente recente que ainda passa por problemas de ordem estrutural - principalmente em relação à plena distribuição tanto do Guia quanto dos livros escolhidos. Não só isso, há ainda problemas de ordem cultural (em termos de resistência), uma vez que não há devido esclarecimento dos pormenores do programa para aqueles que são, definitivamente, os seus destinatários - os professores. Essa falta de informação pode explicar a resistência em utilizar o guia (por exemplo, pelo fato de que muitos professores acreditam que se trata de um impresso com concepções do governo), ou no total desconhecimento da origem do impresso, já que foi recorrente a crença de que se trata de um material produzido e enviado pelas editoras.

As reformulações são recorrentes a cada novo programa. Mas nem sempre os professores conseguem se apropriar das mudanças processadas a cada edição do PNLD. Como foi dito ao longo do texto, as mudanças que vão desde a estrutura do guia até os critérios de avaliação são notórias e necessárias. Por ser tão recente, a cada edição o PNLD é reavaliado, tanto por professores universitários, especialistass da área, quanto pela mídia (como ocorre recentemente ${ }^{10}$ ) e pelos próprios professores que podem, através das suas escolhas, indicar preferências. Apenas nos guias de História de 2005 e de 2008 as mudanças são bastante perceptíveis (mas temos de levar em conta, nesse caso, uma gama de fatores - equipes, leis, mudanças historiográficas, etc.). Não podemos esquecer que o conhecimento, qualquer tipo de conhecimento, só se mantém por ser repetidamente reavaliado, reinterpretado - vivemos em uma realidade dinâmica. Nesse sentido, são necessários estudos não só sobre a produção, mas sobre a recepção dos guias e dos livros. Esses estudos podem também ao mesmo tempo alimentar os debates acerca do livro didático, sobretudo também porque apontam comumente perspectivas

\footnotetext{
"Trata-se cla polêmica en torno do livro provavelmente mais escolhido do PNLD 2008, "Projeto Araribá", que supostamente veicularia propaganda do atual governo.
} 
elaboradas pelos professores no exercício da docência que, não raramente, são diferenciadas daquelas postas em prática por avaliadores do PNLD.

Como já dito antes, são raras as pesquisas que colocam em foco a perspectiva do professor. Com o material que temos fica claro que são poucos os docentes que efetivamente usam o guia produzido pelo governo - os outros ou não usam, ou fazem um uso "ranqueado" (SIMAN, PERERIA e SILVA, 2007, p. 11) (o que é possível com o quadro síntese de 2008). Além disso, outros fatores não podem deixar de ser considerados: a resistência de parte dos docentes ao Guia (inclusive pela crença de que é um produto de apologia governamental) 0 assédio das editoras aos docentes (mesmo que nas últimas edições do PNLD tenha essa prática sido constrangida por impedimentos formais), as dificuldades da prática escolar para criação de oportunidades efetivas de análise e debate do conteúdo do guia, a necessidade de elucidação de critérios de análise dos livros didáticos, em diálogo com o Guia, que atendam às determinadas realidades escolares, a falta de acesso ao Guia e às informações a respeito das condições de sua produção e finalidades, a falta de informação quanto à natureza do guia, a distância entre a lógica acadêmica e a lógica escolar (BATISTA, VAL, 2004), e etc. Claro que existe o outro lado, de utilização, de leitura e amparo do guia por professores em momentos de escolha, mas, ainda sim, o não-uso prevalece. Nesse sentido concluímos que falta aos órgãos públicos responsáveis uma ação de esclarecimento, frente às escolas, assim como mais estudos sobre o tema que sejam acessíveis aos professores. Consideramos que o processo de confecção do Guia do Livro Didático poderia incluir fase de validação, na qual professores da Educação Básica, diretamente implicados na docência naquele nível de ensino ao qual se destina o livro didático em análise, fossem também colaboradores.

0 campo da recepção é, como sabemos, plural e imprevisível. Mas, nesse caso, pode fazer emergir elementos significativos para um amadurecimento também do PNLD, mas, sobretudo da pesquisa acadêmica implicada com a melhoria da Educaç̧ão Básica, em respeito também ao exercício da docência qualificada, reflexiva e de fato protagonista. 


\section{Referências}

BATISTA, Antônio Augusto Gomes e VAL, Maria da Graça Costa (org). Livros de alfabetização do português: os professores e suas escolhas. Belo Horizonte: Ceale/Autêntica, 2004.

BRASIL, Secretaria de Educação Básica. Guia do Livro Didático 2005: História ( $5^{a}$ a $8^{a}$ séries). Secretaria de Educação Básica. - Brasília: Ministério da Educação, Secretaria de Educação Básica, 2006.

Guia do Livro Didático de 2008: História ( $5^{a}$ a $8^{a}$ séries) Secretaria de Educação Básica - Brasília: Ministério da Educação, Secretaria de Educação Básica, 2006.

CASSIANO, Célia Cristina de Figueiredo. Aspectos políticos e econômicos da circulação do livro didático de História e suas implicações curriculares. História, São Paulo, vol. 23, p. 33-48, 2004. Disponível em: http://www.scielo.br/pdf/his/v23n1-2/a03v2312.pdf acesso em: 03/07/2007.

MIRANIDA, Sônia Regina. LUCA, Tânia Regina de. 0 livro didático de história hoje: um panorama a partir do PNL.D. Revista Brasileira de História, São Paulo, vol.24, nº.48, 2004.

SIMAN, Lána Mara de Castro; PEREIRA, Júnia Sales; SILVA, Marco Antônio. Livros didáticos de História: processos de escolha, atores, cenários e tramas.

SIMAN, Lana Mara de Castro, PEREIRA, Júnia Sales e SILVA, Marco Antônio. Livros Didáticos de História: () que Guia as escolhas dos professores?. Encontro Nacional: Perspectivas do Ensino de História. Natal: 2007, 11 p.

Processo de escolha de livros didáticos de História: atores, cenários e tramas. Anais Congresso Livros Escolares - USP, 2007.

SIIVA, Marco Antônio. ANDRADE, Luisa Teixeira. SIIVA, Roseli Correa da. SIMÕES, Júlia M. MOREIRA, Vivian C. Escolhas e usos de livros didáticos de história. Belo Horizonte: Faculdade de Educação, 2007 (Projeto de Pesquisa).

Outras fontes:

Entrevista de Fernando Haddad à CBN: http://portal.mec.gov.br/index.php?option=com_ content\&task= view\&id=9164. 


\section{From Content To Reception: \\ tho Ilistory Textbook Guide (2005-2008)}

\section{ABSTRACT}

The present article deals with the changes of the History textbook's guide from the years of 2005 and 2008 , related both to structural aspects and specific aspects of the historical and pedagogical knowledge. It deals also with the reception of such textbook's guide to teachers from basic education, with focus on the way they use the material and on which factors interferes or influences in the process of choice of the History textbook.

Keywwords: PNLD (National Program of Textbooks), History textbook's guide, way of using the guide, process of choice of textbooks. 